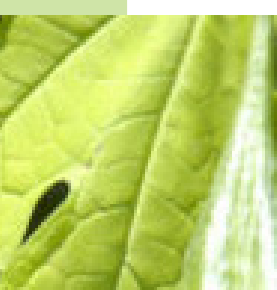

$30 y^{2}$

- 3 .

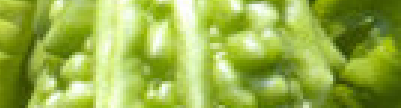
ex 4 )

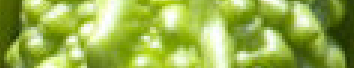
3800120 2ositist

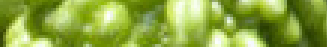

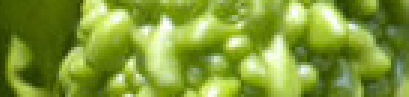
190.80 है 8 is 896 . y. 89.96 Cos 0 as

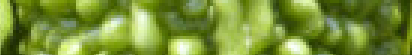

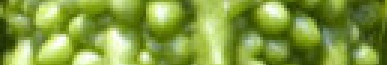
198:3 20 ? 23,39 mences

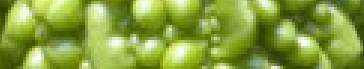
cos (1) 190. secos 89

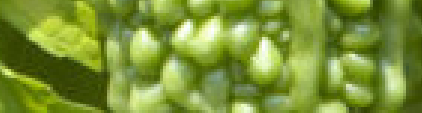

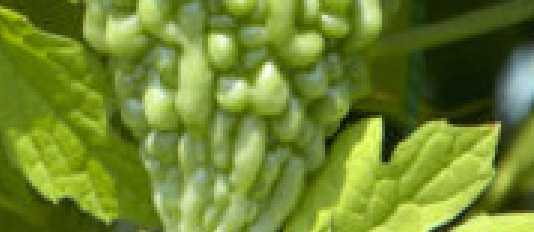

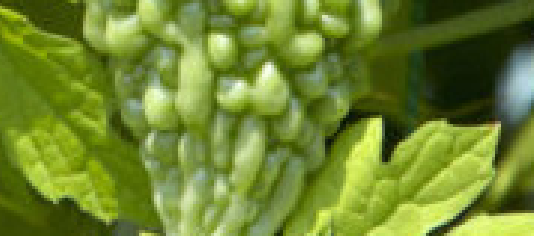
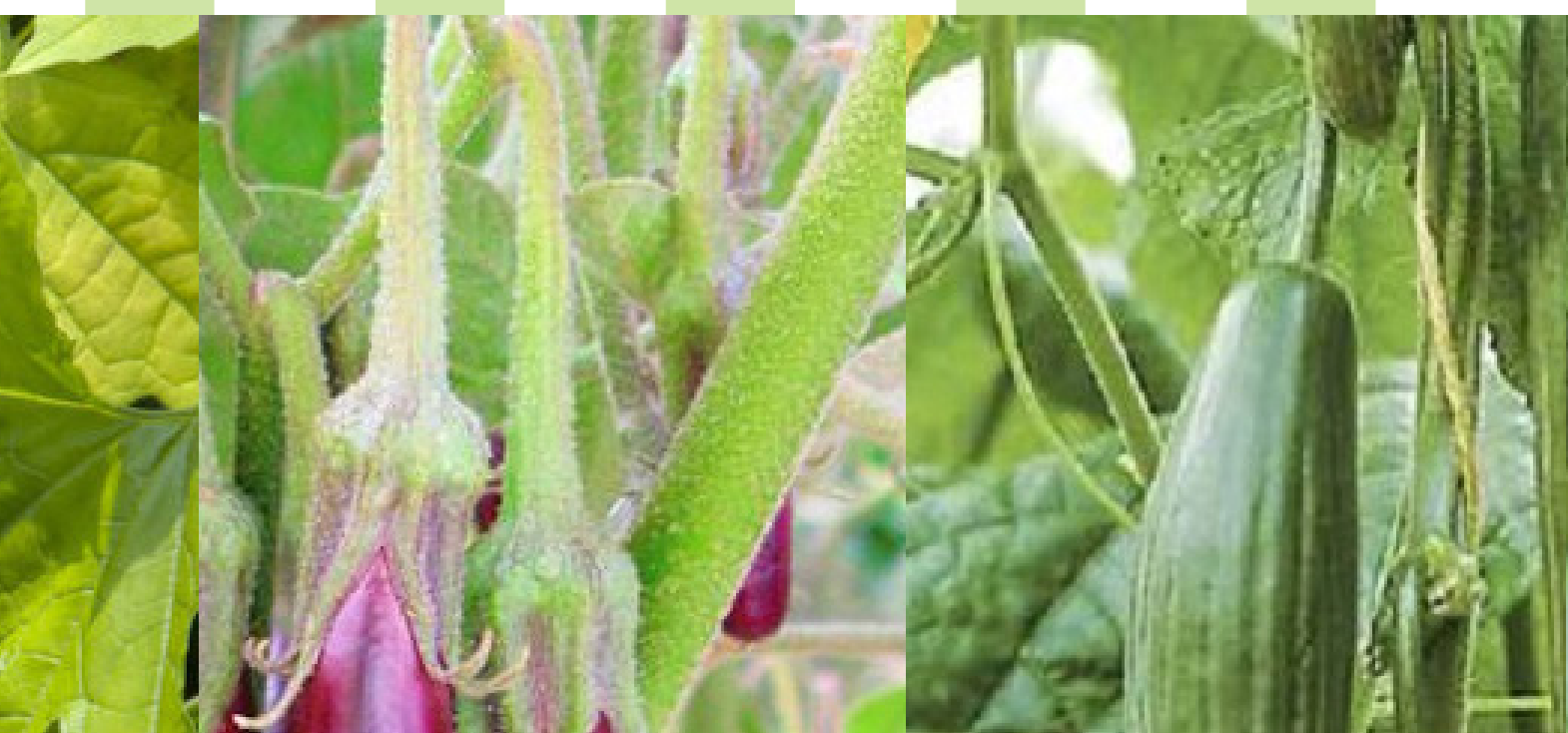

11
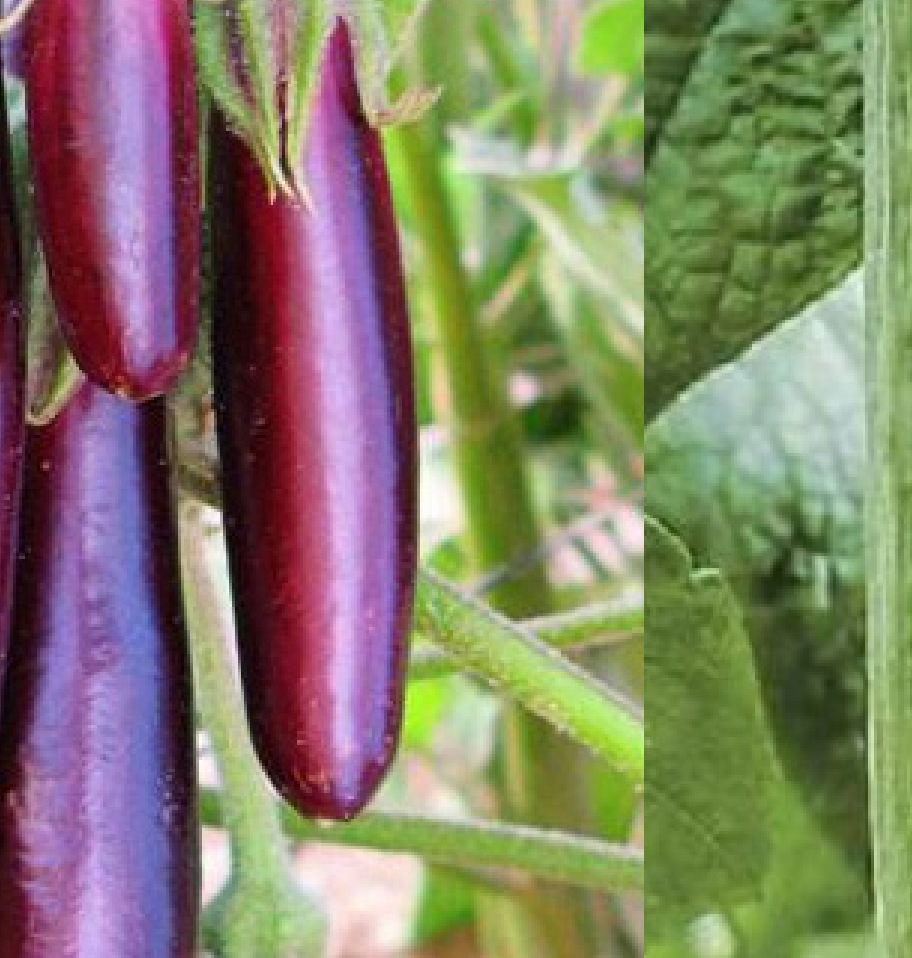


\title{
Cadena global de valor y competitividad de las hortalizas exóticas del estado de Nayarit
}

Global value chain and competitiveness of the exotic vegetable of the state of Nayarit

\author{
Reyna Myrna Paredes Medina \\ Universidad Autónoma de Nayarit \\ Correo electrónico: rm.paredes@uan.edu.mx
}

(Recibido: 19/04/2018. Aceptado: 21/09/2018)

DOI: 10.22201/fe.24484962e.2018.v7n12.a2

\begin{abstract}
RESUMEN
En este artículo se analiza la competitividad de la agroindustria de hortalizas exóticas del estado de $\mathrm{Na}$ yarit a través de la estructura de cadena global de valor con énfasis en la gobernanza de la cadena. El objetivo es identificar la oportunidad de escalamiento en la cadena (upgrading) o de ubicarse como un eslabón menos vulnerable que le permita generar y apropiarse de un mayor porcentaje del valor generado en la cadena (Gereffi, Korzeniewicz y Korzeniewicz,1994). Este enfoque permite visualizar la forma como se articula esa agroindustria a una red regional de producción y de comercialización en Estados Unidos y Canadá. La información se obtuvo de cuestionarios y entrevistas a empresarios y funcionarios de instituciones públicas del sector agrícola. En el estudio se detectaron dos tipos de gobernanza predominantes: la cautiva y la jerárquica. Asimismo, se evidencia la importancia de la agroindustria para la región.
\end{abstract}

Palabra clave: competitividad, cadena global de valor, escalamiento.

Clasificación JEL: O13, O31, O41, O51, Q12, Q17.

\section{ABSTRACT}

This article analyzes the competitiveness of the exotic vegetable agribusiness of the state of Nayarit through the structure of the global value chain with emphasis on the governance of the chain. The objective is to identify the opportunity of escalation in the chain (upgrading) or to position itself as a less vulnerable link that allows it to generate and appropriate a greater percentage of the value generated in the chain (Gereffi, Korzeniewicz and Korzeniewicz, 1994). This approach allows us to visualize the way in which this agroindustry is articulated to a regional production and marketing network in the United States and Canada. The information was obtained from questionnaires and interviews with businessmen and officials of public institutions in the agricultural sector. In the study, two predominant types of governance were detected: captive and hierarchical. Also, the importance of agro-industry for the region is evident.

Key words: Competitiveness, global value chain, upgrading.

JEL Classification: O13, O31, O41, O51, Q12, Q17. 


\section{INTRODUCCIÓN}

E l enfoque de cadena global de valor (CGv) es una herramienta que permite entender la dinámica de organización de un nuevo modelo de producción flexible y globalizado. Si bien es cierto que la producción de hortalizas de origen asiático es una producción globalmente desarrollada, el análisis de la participación de la agroindustria nayarita se desempeña como una cadena macrorregional ya que sólo se vincula a los mercados hortícolas de Estados Unidos (EE. UU.) y Canadá. En esta región las agroindustrias llevan a cabo transacciones y arreglos comerciales que, de acuerdo con Gereffi (2001), van desde arreglos de mercado hasta arreglos intrafirma o jerárquicos, e involucra actividades de empresas jurídicamente independientes en una coordinación transfronteriza de cooperación y competencia entre Canadá, EE. UU. y México.

En el análisis, la gobernanza es determinante para el desempeño y evolución de la cadena tanto de la competencia como de los factores que desarrollan para competir. En este sentido, el papel que juegan las cadenas de distribución y de supermercados es fundamental. La importancia radica en que la dinámica de la cadena establece la forma, las restricciones y las oportunidades en las que las agroempresas nayaritas se vinculan a ella, pero sobre todo determina las oportunidades que tienen la agroindustria y/o las agroempresas para escalar en la cadena.

Esta cadena global de valor se estructura de eslabones de producción en América Latina (principalmente en México), de centros de distribución en América del Norte (Canadá y EE. UU.) y cuenta con mercados en EE. UU., Canadá, Europa y Asia; hacia atrás, cuenta con el eslabón de insumos que se encuentra en EE. UU., Canadá y, eventualmente, en Asia.

\section{ESTRUCTURA Y GOBERNANZA DE LA CGV DE HORTALIZAS EXÓTICAS ${ }^{1}$}

Como resultado del auge que han tenido las grandes cadenas de distribución y de supermercados en Norteamérica (EE. UU. y Canadá) en el comercio de frutas y verduras, éstas han alcanzado un alto grado de control en la producción de hortalizas frescas de importación procedentes de América Latina, incluyendo México. Dichas cadenas, de distribución y de supermercados, se caracterizan por tener una competencia oligopólica que compite por la lealtad de los clientes y por mantener o incrementar su participación en el mercado. Asimismo, y dada la tendencia hacia una alimentación cada vez más sana, las estrategias de competencia que utilizan estas cadenas son: la trazabilidad de frutas y hortalizas, la diferenciación de productos, la oferta de una variedad de productos frescos cada vez más amplia y la oferta de productos semipreparados. En la actualidad, las frutas y hortalizas frescas son un área clave de la competencia entre supermercados (Dolan y Humphrey, 2001). La fuerte presión competitiva a la que están sometidas estas grandes cadenas hace que jueguen un papel decisivo en la participación y desarrollo de agroempresas exportadoras en la cadena de suministro, como ha sido para la agroindustria de hortalizas exóticas en el estado de Nayarit. Cabe señalar que el suministro de productos de exportación a estas cadenas de supermercados está orga-

\footnotetext{
El término se refiere a aquellas hortalizas que no son endógenas de la región, en este documento se refiere a las hortalizas de origen asiático que se cultivan en la región norte del estado de Nayarit.
} 
nizado, a su vez, por un número importante de empresas comercializadoras y brókeres que conforman un nodo más en la cadena y que, a su vez, ejercen gran presión en sus proveedores hortícolas.

Esta presión determina la ubicación y el desempeño de las empresas productoras de hortalizas exóticas en el estado de Nayarit dentro de la cadena, quedando relegadas a un papel secundario, en donde las grandes cadenas de supermercados y de distribución, a través de las empresas comercializadoras y los brókeres a los que abastecen, son las que establecen las condiciones de producción y los estándares de calidad a los productores hortícolas. Este control de la cadena deriva de dos factores, el primero es la amplia gama de estrategias de competencia utilizadas por las cadenas de supermercados y de distribución que se basan en la variedad, la calidad y la desestacionalidad de los productos hortícolas; y un segundo factor es la creciente preocupación por el cumplimiento de las normas de seguridad alimentaria, con el fin de garantizar la inocuidad de los alimentos; estas normas se aplican a cualquier organización que se encuentre dentro de una cadena alimentaria, independientemente de su tamaño y su posición dentro de ella, incluso a los productores independientes.

En concordancia con Dolan y Humphrey (2001), la gobernanza en la cadena de hortalizas exóticas se hace necesaria porque los proveedores carecen de competencia técnica, o conocimiento del mercado, y es muy costosa la curva de aprendizaje, tanto que son pocas empresas y muy pocos productores independientes los que logran superarla y establecerse de manera más permanente. Una excepción a este señalamiento es cuando el vínculo que establece la agroempresa con la empresa comercializadora es de tipo jerárquico, pues este vínculo hace posible soportar los gastos que implica la curva de aprendizaje porque es la empresa comercializadora la que absorbe este gasto.

En el caso de productores independientes. lo que les permite superar esta barrera es la asistencia técnica otorgada por la agroempresa exportadora a la que se afilian, sin embargo, dicha agroempresa no comparte ningún riesgo con el productor independiente. El hecho de que las empresas comercializadoras hayan optado deliberadamente por no participar directamente en la producción de hortalizas les ha permitido especializarse en la organización de la cadena de suministro, pudiendo ejercer mayor presión debido a que no son ellas las que asumen los riesgos de la producción y transporte, sino las agroempresas exportadoras y, en su caso, los productores independientes. No obstante, esta rigidez en el control de los estándares de calidad de los productos se vuelve flexible cuando en el mercado se requiere un suministro adicional de los productos hortícolas.

La estructura de la CGV de hortalizas de origen asiático y la posición que guarda en ella la agroindustria nayarita han limitado a esta última a la búsqueda de tácticas para abatir costos como estrategia competitiva, a través de innovaciones tanto en el proceso de producción agrícola como en el proceso administrativo; esto implica tanto la utilización de tecnología mejorada a lo largo de todo el proceso de producción como a la adopción de buenas prácticas agrícolas para lograr la inocuidad de los productos hortícolas ofrecidos.

Para un análisis completo de la CGV, Pelupesy (2001) propone cuatro dimensiones básicas que permiten apreciar la dinámica de la cadena y evaluar el impacto de la globalización en la creación de competitividad estructural de la CGV: 1) insumo-producto, 2) ubicación, 3) contexto institucional y 
4) estructura de la cadena. Para la agroindustria nayarita se encontró lo referido a continuación:

\subsection{Insumo-producto}

En la CGV de hortalizas, la agroindustria nayarita de hortalizas exóticas conforma un eslabón de bajo valor agregado, que se compone de cinco nodos básicos:

Insumos. La mayoría de los insumos requeridos en todo el proceso de producción y empaque son importados. Entre los insumos requeridos en el proceso de producción agrícola se encuentran tanto los agroquímicos (fertilizantes, abonos, pesticidas, etc.) como las semillas de variedades o calidades específicas (semillas de cucurbitáceas, básicamente de Bitter melon y Sinqua, las cuales se traen de Taiwán), cuya producción recae en grandes empresas como Syngenta, Monsanto, Dupont, Bayer, que se han especializado en dicha producción y que de cierta forma tienen el control del mercado en la región. Por lo tanto, estos productos son sólo comercializados dentro del país y, en el mejor de los casos, el proceso de embasamiento y distribución al interior se realiza por pequeñas empresas nacionales. Aunque el valor agregado en esta actividad es bajo, representa una oportunidad de ingresos para la economía nacional.

Por otro lado, las especies y variedades de semillas de hortalizas que se cultivan en el estado de Nayarit está muy controlado por las mismas empresas comercializadoras y brókeres. El control que se tiene sobre este insumo permite de igual forma mantener el control del proceso por parte de la empresa integradora, en este caso "el cliente" (SSK y Bitter Vegetables), y en el caso de los productores independientes la única forma de acceso es a través de la agroempresa a la que se integró. Sin embargo, esta dependencia, que al principio era casi total, ha ido modificándose a lo largo de los aproximadamente 25 o 30 años en que se introdujeron estos cultivos en el estado, siendo tal que en algunas variedades se seleccionan los frutos que servirán de semillero para la siguiente siembra y las reproducen en sus invernaderos. La creación de invernaderos es una de las técnicas que se han difundido a raíz del desarrollo de estos cultivos, ya que algunas variedades requieren de la germinación de la semilla y el trasplante cuando la plántula llega a cierto desarrollo.

Otras categorías de insumos son aquellos que se producen dentro del territorio nacional, aun cuando no sea dentro de la localidad o la región. En esta categoría encontramos a los conservadores a base de cítricos, utilizados para algunas especies de hortalizas. El caso de los conservadores a base de cítricos es interesante porque se desarrolla al interior del país por una pequeña empresa ubicada en la Ciudad de México, cuyo uso proporciona ventajas a los productores agrícolas, ya que les permite una mayor vida de anaquel al producto y tienen, por tanto, mayor margen de manejo poscosecha.

Algunas de las variedades de semillas, sobre todo las que no se producen en EE. UU., son difíciles de importar, dada su escasa distribución. En este sentido, cabe mencionar que, por lo general, estas variedades se introducen al país como una transacción trunca, en donde son básicamente abastecidas por la empresa comercializadora a la que proveen sin tener que pasar por el mercado e incluso por la aduana; aun así, el costo de la semilla es muy elevado. Asimismo, otros insumos que, aunque no son altamente especializados o escasos, también son proporcionados por las empresas comercializadoras, como 
CUADRO 1

PROVEEDORES DE INSUMOS DE LA AGROINDUSTRIA DE HORTALIZAS EXÓTICAS

\begin{tabular}{|l|l|}
\multicolumn{1}{|c|}{ Industria } & \multicolumn{1}{c|}{ Empresas } \\
\hline Semillas & Sakata Seed America Inc., Western Pacific Seed Inc. y Known You Seed Co. \\
Agroquímicos & Bayer Group Science y Du Pont \\
Maquinaria y equipo & John Deer, CNH y las empresas comercializadoras a las que proveen \\
Otros insumos & Empresas comercializadoras \\
\hline
\end{tabular}

Fuente: elaboración propia con base en entrevistas con los productores.

las cajas de cartón para el empaque de las variedades de calabaza, berenjena y Okra, vienen con el logotipo de la empresa comercializadora de EE. UU. o de Canadá. Además de los insumos, estas empresas son las que realmente tienen los vínculos comerciales con las cadenas de tiendas de autoservicio, los mayoristas y restaurantes chinos.

Dentro de la CGV de las hortalizas, los insumos son uno de los eslabones que mayor valor agregado retienen. Según información obtenida con los productores, el consumo de agroquímicos representa hasta el 70\% del costo de producción en las hortalizas exóticas. Otros insumos que requiere la agroindustria nayarita son cajas de cartón, jabas y tarimas, que obtienen directamente de la empresa comercializadora con la que se encuentra vinculada cada agroempresa nayarita productora de hortalizas; si no es el caso, las tienen que importar.

Producción hortícola. El proceso de producción agrícola es la actividad fundamental que se realiza dentro del territorio nacional. La tierra, como principal factor de producción, tiene dos modalidades de tenencia: la propiedad y el arrendamiento. El arrendamiento de tierras es una modalidad muy utilizada por los productores de hortalizas por dos razones: la primera, y fundamental, es por la variabilidad en la demanda de su mercado, la cual depende en gran medida de las condiciones climáticas que se presenten en EE. UU. y Canadá y la variabilidad de la oferta para esos mercados; la segunda es por la variabilidad en los precios de las tierras y, adicionalmente, por la práctica de rotación de cultivos. En este proceso también se utilizan insumos que en su mayoría son importados pero comercializados al interior por empresas nacionales, tales productos son: los sistemas de riego, por lo regular son las mangueras que se utilizan para el riego por goteo, aunque algunas empresas utilizan aspersores; la maquinaria, aunque es variada lo básico son los tractores, los cuales se requieren de dos capacidades, una de mayor potencia para la preparación de la tierra antes del cultivo y otros de menor capacidad para el uso dentro de los cultivos.

El cultivo de hortalizas la pueden llevar a cabo tanto las empresas de la región como los productores independientes debido a que se puede efectúan con baja tecnificación en el proceso, lo que permite que los pequeños productores puedan ser competitivos, sobre todo en algunas de las especies que se comercializan con mayor flexibilidad, como lo son las calabazas y los ejotes en sus distintas variedades.

El abastecimiento de fuerza de trabajo es importante en este eslabón de la cadena, ya que se caracteriza por ser intensivo en fuerza de trabajo (65 jornaleros/hectárea durante todo el proceso). La oferta de fuerza 
de trabajo en países en desarrollo, como el nuestro, es abundante, lo que es aprovechado por los países desarrollados en la explotación de estos productos agrícolas, por lo que son ubicadas en economías en vías de desarrollo donde la fuerza de trabajo, por ser abundante, se puede conseguir muy barata (oscila entre 80 y 150 pesos por jornal).

En entrevista con los productores, señalan que donde más personal se necesita es en la cosecha, requiriendo hasta 500 trabajadores jornaleros por día en temporada alta. Generalmente, la contratación de jornaleros se hace de manera directa en la localidad llamada Guadalupe Victoria (comúnmente conocida como La Virocha) donde se aglutinan jornaleros de distintas partes de la República Mexicana (Guerrero, Oaxaca y Chiapas principalmente), así como indígenas de la región (Coras, Huicholes, Tepehuanos y Mexicaneros) que buscan ser contratados. En las otras fases de desarrollo es poca gente la que se requiere y el personal de base o permanente asciende a alrededor de 60 trabajadores.

Aunque la temporada fuerte de los cultivos exóticos es de octubre a mayo, puede haber producción durante todo el año, especialmente de algunas especies como la del ejote en sus distintas variedades; esto significa que la derrama en salarios, aunque baja, es constante. Esto ha resultado favorable para el desarrollo de la región debido a que permite llevar a cabo proyectos a más largo plazo por parte de los jornaleros locales y de aquellos que deciden arraigarse en las localidades donde se encuentran las empresas o en localidades aledañas.

Otro rubro importante en el desarrollo de esta fase de producción es la utilización de técnicas de riego, en las cuales se requiere tanto de productos importados como del conocimiento de las técnicas para la adecuada utilización y optimización del recurso. En este sentido, los cultivos de hortalizas se diferencian del resto de la actividad económica de la región, e incluso de la actividad agrícola nacional, ya que la mayoría de los cultivos en el estado son de temporal; por otro lado, el rendimiento por hectárea y el valor por hectárea en estos cultivos es superior, por mucho, al promedio de los cultivos típicos.

Acopio. Esta función la llevan a cabo dos de las agroempresas de la agroindustria, a saber, ZSK en Tuxpan, Nayarit, y San Carlos en Santiago Ixcuintla, Nayarit, quienes otorgan asesoría empírica sobre lo que requiera el productor independiente, que puede ser desde la preparación de la tierra, el uso de agroquímicos, especificidades de las variedades cultivadas hasta el manejo poscosecha de los productos hortícola. El acopio tiene dos modalidades. En una primera instancia el productor independiente vende a granel su producto, dejando a la agroempresa, que acopia los procesos de selección y/o clasificación, el proceso de conservación (si se requiere) y empacado del producto para su transportación. Una segunda modalidad es que el pequeño productor se encargue de clasificarlo, empacarlo y llevarlo hasta la acopiadora, quien se encarga del resto del proceso, es decir, del transporte y la comercialización.

A nivel macrorregional, la empresa San Carlos, que cuenta con una filial en San Diego California, EE. UU., puede fungir como acopiadora para productores nacionales. En este sentido, dicha empresa puede realizar las funciones de cualquier compañía comercializadora, aglutinando la producción de pequeños productores independientes de la región norte del estado de Nayarit. Esto podría dar mayor presencia a la empresa nayarita y mayor participación en dicho mer- 
cado. Fortalecer este eslabón de la cadena puede ser la oportunidad para mejorar las condiciones de negociación de los productores nacionales y no sólo de los nayaritas.

Empacado. Sólo dos de las agroempresas de la agroindustria cuentan con las instalaciones para poder procesar y refrigerar el producto para su conservación, estas son las mismas que fungen como acopiadoras. Cabe señalar que la separación de los procesos es únicamente para hacer evidente las relaciones de alianza o el sistema de cooperación entre los pequeños productores o productores independientes, pues estas dos actividades, acopio y empaque, se lleven a cabo en un proceso que realiza la misma agroempresa.

Las agroempresas cuentan con un área y equipo para el empaque, como bandas para la selección y clasificación de los productos que así lo requieren; algunas de ellas cuentan con una cámara de enfriamiento y otra de refrigeración para la conservación de los productos, una vez seleccionados y empacados. En algunas variedades el proceso de selección y clasificación se realiza en campo y se transporta a la empacadora sólo para su conservación antes del transporte. Para las variedades que requieren un minucioso proceso de selección, y en el caso del producto acopiado, el proceso de empaque inicia con la selección y clasificación del producto, en el cual se realiza fundamentalmente con fuerza de trabajo femenina (en temporada alta se contratan alrededor de 15 a 20 obreras por empacadora).

Una vez seleccionado y clasificado el producto se procede a su empaque. De acuerdo con sus características, se utilizan dos tipos de empaque principalmente: la caja de corrugado (cartón) de diferentes tamaños y con diferente estampado según el producto; estas cajas se utilizan especialmente para las diferentes variedades de calabaza, el Bitter melon y la flor de plátano. Este empaque es proporcionado por el "cliente", es decir, la empresa comercializadora o el bróker, y por supuesto no es de fabricación nacional.

El otro tipo de empaque que se utiliza son las cajas de madera, conocido también como rejilla, huacal o jaba, que es el que requiere el ejote para ser transportado. Este tipo de empaque tiene dos ventajas relativas para la economía regional: 1) siendo un artículo que se puede desestacionalizar, ello le permite ser fuente de ingresos permanentes para la localidad a través de la derrama salarial a lo largo de casi todo el año; 2) se cuenta con la posibilidad de volver a producir la rejilla o huacal que con anterioridad se elaboraba en los estados de Zacatecas y Guanajuato, lo cual se presenta como una oportunidad de desarrollo para la industria de huacales y como una ventaja de costos para la agroindustria de hortalizas.

Asimismo, se generarían encadenamientos hacia atrás al crear vínculos más consistentes con la economía regional, sirviendo así de arrastre en ese sector; adicionalmente, la agroindustria cuenta con una cámara de esterilización de madera tanto para jabas (huacales) como para tarimas para embalaje, la cual se ubica en la agroempresa de Santiago, siendo la única en la región que ofrece el servicio a otras agroempresas, no sólo a las de la agroindustria de hortalizas exóticas; lo anterior la convierte en un nodo importante de la producción, además de generar vínculos más fuertes con la economía local.

Transporte. El traslado de las hortalizas tiene tres fases. La primera es del campo a la empacadora, que se realiza en camionetas pick up propiedad de las agroempresas o del productor independiente. La segunda fase 
consiste en transportar el producto de la agroempresa a la frontera, lo que se realiza a través de los servicios de empresas especializadas en el ramo que suelen ser nacionales, aunque anteriormente el traslado se realizaba en tráileres estadounidenses, ya que la agroindustria no contaba con el transporte requerido, básicamente con sistema de refrigeración; solo en uno de los casos el servicio de transporte sigue siendo extranjero y en otro la agroempresa cuenta con su propio transporte especializado. El servicio generalmente se contrata hasta la aduana de la frontera norte, donde los brókeres los reciben y se encargan de transferir el producto del tráiler nacional al tráiler extranjero o en el mejor de los casos se encarga de enganchar la caja del tráiler a otro estadounidense para ser transportado a su destino final que, a decir, comprende la tercera fase de este nodo. El destino final puede ser una bodega ubicada en algún punto estratégico del mercado (California), donde el cliente pasa a recoger la mercancía o es directamente llevada hasta las instalaciones del cliente (empresas comercializadoras ya mencionadas, SSK, Big Best, etc.). En temporada baja (primavera-verano) la bodega funciona como comercializadora, en donde se ofrece el producto al mercado abierto. Algunas de las agroempresas nacionales prefieren contratar servicio de transporte estadounidense porque es más fácil su paso hacia el país vecino, en términos de trámites administrativos y aduanales.

Comercialización. La comercialización y distribución de las hortalizas son el último eslabón de la cadena; cabe señalar que éste es el eslabón más importante, pues es el que organiza al resto de la cadena. Gereffi (2001) y Gereffi, Lee y Christian (2009) señalan que en las CGv la gobernanza ha dado un giro respecto a cómo y quién organiza las actividades productivas, ésta ha pasado de ser conducida por empresas productoras a ser conducidas por empresas comercializadoras; este es el caso de la CGV de las hortalizas exóticas. En este tipo de gobernanzael cliente es el que determina las características de la producción completa, desde los estándares de calidad hasta el volumen de producción y grado de tecnificación de los procesos. Este control es posible gracias a la inversión directa hacia este sector. De esta manera, la inversión extranjera directa (IED) tiene un papel importante en la nueva división del trabajo y en la especialización productiva, al establecer los cambios a nivel mundial promoviendo determinados productos en ciertas regiones. El efecto más inmediato es la especialización de los países periféricos en aquellas actividades que les permite insertarse en el mercado mundial al ligarse a las empresas multinacionales.

Es destacable señalar que la industria hortícola de Nayarit ha logrado establecerse en este eslabón, apropiándose de un porcentaje mayor del valor dentro de la cadena que el eslabón de producción. Este esfuerzo significa un avance para la industria nayarita toda vez que participa en dos eslabones de la cadena y, como ya se indicó, es uno de los eslabones que tiene una incidencia significativa en la producción de hortalizas.

\subsection{Ubicación}

La cadena de hortalizas exóticas se ubica en la región norte de América, distinguiéndose dos zonas de actuación en el proceso. Una zona es EE. UU. y Canadá, economías desarrolladas donde se ubican las empresas productoras de insumos con alto contenido tecnológico y científico, como las semillas, herramientas y maquinaria de labranza, de refrigeración y equipo especializado para el 
FIGURA 1

INSUMO-PRODUCTOY UBICACIÓN GEOGRÁFICA DE LOS NODOS EN LA CGV DE LAS HORTALIZAS EXÓTICAS DEL ESTADO DE NAYARIT

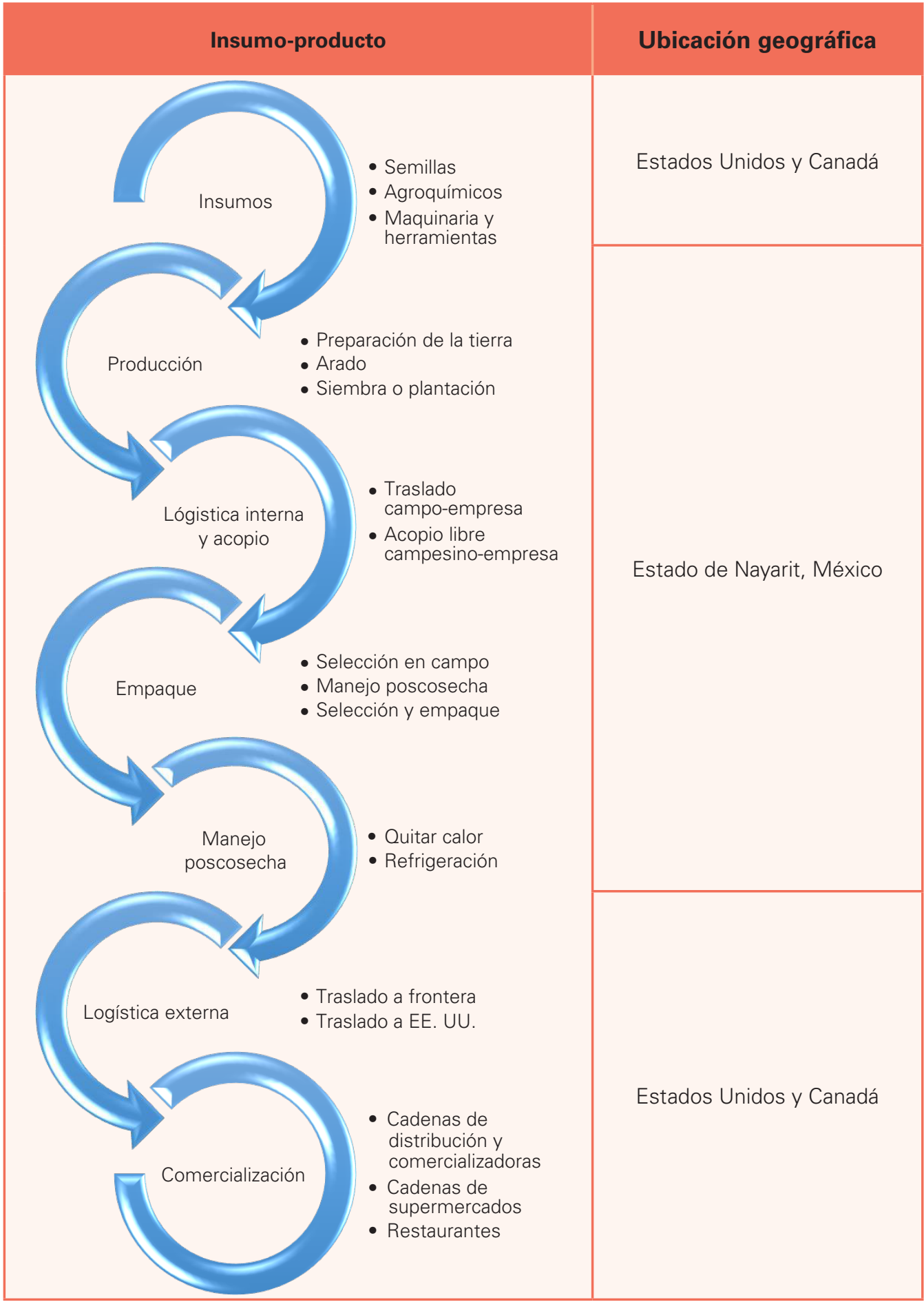

Fuente: elaboración propia con base en investigación de campo. 
transporte. Por otro lado, también es donde se ubica el nicho de mercado donde se comercializa una gran cantidad de frutas y hortalizas. Por ende, es donde se ubican las empresas que lideran la cadena. Estas empresas, trasnacionales y corporaciones globales, controlan no sólo los canales de distribución sino también el acceso a la cadena misma y a los recursos importantes que requiere, como el diseño de productos, tecnología y el contacto con los puntos de venta (cadenas de supermercados, restaurantes y comercio de mayoreo y medio mayoreo).

La otra zona son las economías en desarrollo, como México, que asumen actividades intensivas en fuerza de trabajo y son proveedoras de recursos naturales. Además, la producción de hortalizas de origen asiático en el estado de Nayarit atiende a factores que le permiten ser competitiva dentro de la cadena debido, principalmente, a las características climatológicas de la región, generando ciclos complementarios con la producción hortícola en EE. UU. y Canadá y abasteciendo, especialmente, estos mercados en el ciclo otoño-invierno. Sin embargo, aunque el estado provee un clima adecuado y fuerza de trabajo abundante, el desarrollo y pervivencia de la agroindustria nayarita se debe a que ha desarrollado capacidades tecnológicas en el cultivo de este tipo de hortalizas (know how). Adicionalmente, la proximidad geográfica es otro factor importante no sólo para desarrollar el know how, sino también para la creación de redes de cooperación tanto intra como interfirma. Asimismo, la relativa cercanía de la agroindustria nayarita con su mercado objetivo (Florida, California y Canadá) es un factor que incide y que permite tener una interacción estrecha, lo que define el desarrollo de la agroindustria nayarita y de la región donde se inserta. No obstante, es conveniente recordar que, finalmente, el acceso y permanencia en el mercado lo determina la capacidad de respuesta que tienen las agroempresas nayaritas a las exigencias que imponga su nicho de mercado y a las normas que éste establece: calidad, fiabilidad, volumen, rapidez de entrega, así como normas y reglamentaciones (Centro de Comercio Internacional, 2003).

\subsection{Contexto institucional}

El entramado institucional del estado de Nayarit se encuentra instituido formalmente, sin embargo, no significa un soporte real para la agroindustria hortícola nayarita. Si bien es cierto que existen programas de apoyo financiero, técnico y de investigación, a través de instituciones locales y federales, el acceso a ellos por parte de los productores se ve limitado, por un lado, por la forma de competencia a la que son sometidos, como afirma Garammont (2010): "ser competitiva significa poder elevar su productividad mientras los costos de los insumos suben y los precios de las hortalizas bajan", lo que ha ocasionado la pauperización de la agroindustria, viéndose limitada en invertir si no es estrictamente necesario. Por otro lado, la dependencia comercial y financiera con EE. UU. y Canadá hace que se mantenga una débil relación entre la agroindustria y las instituciones nacionales.

En cuanto a las instituciones de financiamiento, la agroindustria recurre muy poco a ellas y accede a créditos personales $y$ en algunas ocasiones al Banco Nacional de Comercio Exterior (Bancomext). Para la agroindustria nayarita es más fácil obtener financiamiento a través de la IED. 


\section{FIGURA 2}

ACTORESY CONTEXTO INSTITUCIONAL

\section{DE LAS HORTALIZAS EXÓTICAS DEL ESTADO DE NAYARIT}

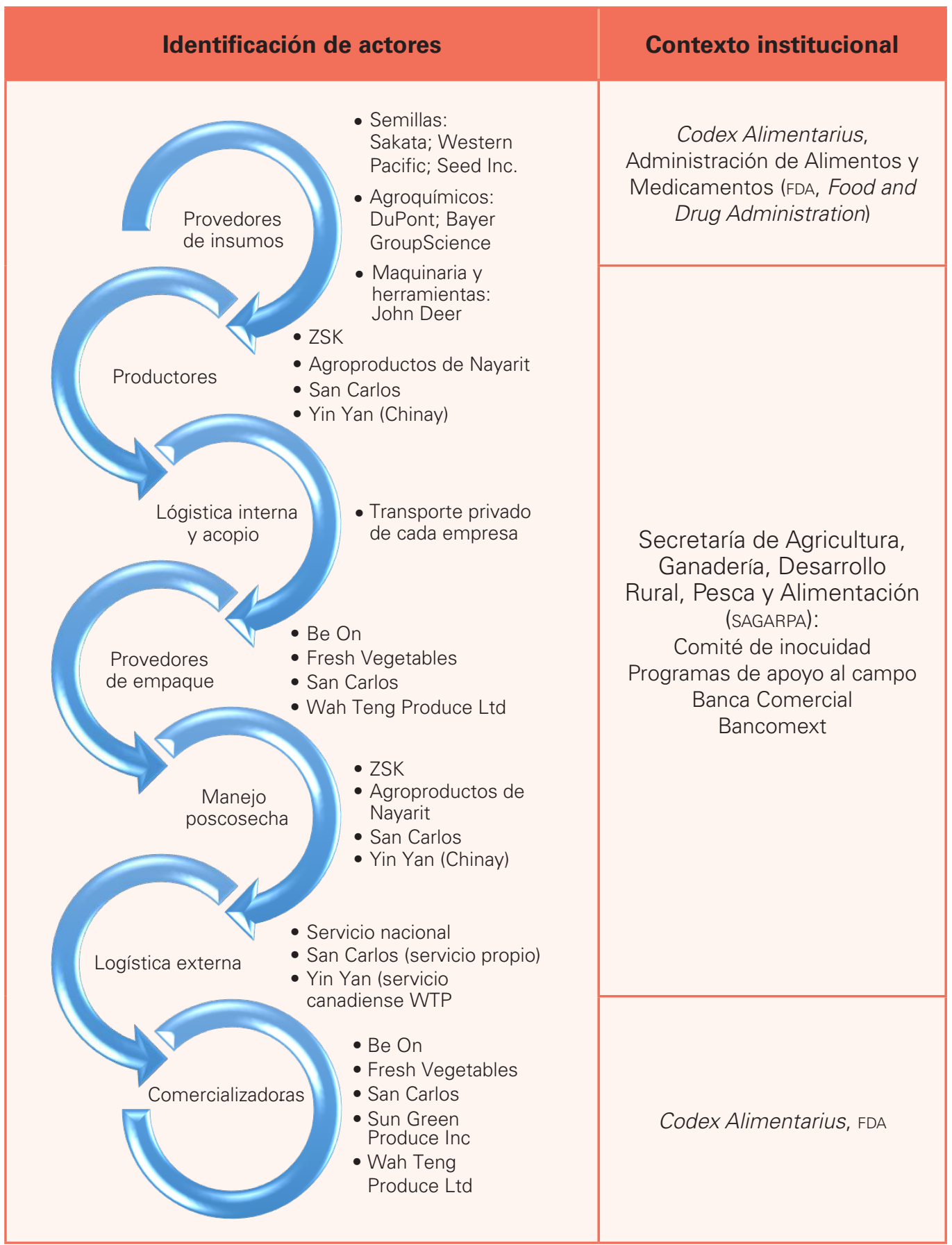

Fuente: elaboración propia con base en investigación de campo. 


\subsection{Estructura de la cadena}

En la CGV de las hortalizas exóticas se distinguen tres patrones predominantes de los cinco patrones mediante los cuales se ejerce la gobernanza dentro de la cadena que describen Gereffi, Humphrey y Sturgeon (2005), señalando que éstos no son estáticos, pero están asociados a las capacidades de los proveedores reales y potenciales para cubrir los requisitos de la transacción. Continuando con el planteamiento de Gereffi et al. (2001) y Gereffi, Humphrey y Sturgeon (2005), los patrones de gobernanza que se distinguen en la agroindustria nayarita son:

Modulares. Los pequeños y medianos productores de hortalizas de las cadenas de valor producen las hortalizas de acuerdo con las especificaciones que solicita su cliente, la comercializadora, le demanda; estas especificaciones son más o menos detalladas en cuanto al proceso de producción, pero muy específicas en cuanto a estándares de inocuidad. Existen casos en los que se proveen servicios intra o interfirma en la cadena, en los que los distribuidores asumen la responsabilidad total en cuanto a la calidad de los procesos tecnológicos, usando maquinaria genérica que limita la transacción en inversiones específicas, y hacen gastos de suma importancia para los componentes y materiales en beneficio de los consumidores.

Cautivas. En estas redes de pequeños y medianos productores, los proveedores de hortalizas son transaccionalmente dependientes de grandes compañías comercializadoras que son sus compradores y, en la mayoría de los casos de la agroindustria del estado, únicos clientes. Los productores afrontan grandes gastos de conmutación, por tanto, son cautivos. Esta red de pequeñas y media- nas empresas productoras y de productores independientes tiene un alto grado de control y monitoreo por parte de las empresas comercializadoras, que son las firmas líderes en la cadena de valor de las hortalizas exóticas.

Jerárquica. Este tipo de relación ha sido la forma característica de ingreso a la CGV de las hortalizas exóticas en el estado de Nayarit. Ha evolucionado hacia una relación modular y cautiva. Este tipo de relación la mantiene sólo una empresa en la actualidad. La forma de coordinar es a través del control directivo de la empresa matriz en Canadá a la empresa filial en Nayarit. Es desde Canadá donde se decide qué variedades se van a cultivar, qué volumen y cualquier situación que se presente en relación a la empresa ubicada en Nayarit.

\section{CONCLUSIONES}

Las CGV son posibles por el grado de desarrollo del sistema capitalista actual que se caracteriza por posibilitar una estructura de producción global; la agroindustria de alimentos es unreferente de este nuevo escenario y el enfoque de CGV permite apreciar el papel que juega la agroindustria nayarita en la estructura global de producción de hortalizas de origen asiático, cómo y quién organiza la producción, dónde se genera el valor agregado y quién se apropia del valor.

En la estructura de la CGV de las hortalizas exóticas, el suministro de los insumos básicos para su producción se localiza en EE. UU. y Canadá principalmente. Su producción y distribución se lleva a cabo por corporaciones globales y grandes trasnacionales que tienen el control de mercado mundial. Por lo mismo, se vuelve difícil competir con ellas; es el caso de la industria semillera en México, cuya capacidad para incursionar 
en esta industria está fuertemente limitada por el grado de inversión que requiere. Esta situación sujeta a esta agroindustria nayarita a una dependencia de la que difícilmente puede salir sin una estructura de apoyo en la que participen activamente instituciones gubernamentales que realicen investigación y desarrollo $(\mathrm{I}+\mathrm{D})$ y que puedan asumir la fuerte inversión (o parte de ella) que se requiere para establecer las condiciones de desarrollo de industrias que den soporte a la agroindustria de hortalizas de origen asiático.

De la misma forma, estas economías (EE. UU. y Canadá) concentran a las grandes empresas comercializadoras que articulan a agroempresas que se ven obligadas a someterse a fuertes presiones para elevar su productividad para ser competitivas y poder permanecer en la cadena. En los eslabones de producción primaria, como es el caso de la agroindustria nayarita, el incremento de la productividad está fuertemente ligada al precio de la fuerza de trabajo y a la explotación de recursos naturales. Como ya se mencionó, estas economías también tienen el control de la cadena y, por tanto, la mayor apropiación de valor generado en esta, sin embargo, la articulación de la agroindustria de hortalizas a la cadena global de hortalizas puede ser la puerta de entrada para insertarse en eslabones con mayor valor agregado (upgrading) y poder competir bajo condiciones que sean más favorables tanto para la agroindustria nayarita como para las regiones que se articulen a esta dinámica.

Articularse a estas cadenas globales ha sido la forma en la que las economías en desarrollo han logrado articularse a los mercados mundiales, y si bien ha sido una oportunidad de desarrollo para el sector agrícola de estos países, particularmente para las regiones en donde se insertan estos eslabones, también las sujeta a un desarrollo limitado en términos de la dependencia que mantiene en cuanto al acceso de insumos y de financiamiento, obligándolas a competir a partir de abatir costos (fuerza de trabajo) que no pueden ser sostenibles en el largo plazo, y no a través de elevar la productividad por desarrollo tecnológico. Pérez (2001) señala que las oportunidades de saltar a posiciones de desarrollo más elevados para las economías en desarrollo se encuentran en las etapas de transición de desarrollo tecnológico mundial, "durante estos tiempos frenéticos se aprende el nuevo paradigma mientras que el viejo se desprende gradualmente" (Pérez 2009) y es en esta transición en el que la agroindustria puede aprovechar la tecnología existente en las economías desarrolladas, y la cuál están posicionando en regiones menos desarrolladas. Al mismo tiempo, es imprescindible desarrollar capacidades tecnológicas que le permitan apropiarse de esa tecnología existente e ir más allá, implementando procesos de innovación de manera continua para ser competitivos bajo otros factores más sólidos.

Entre las opciones que esta red de producción ofrece para el desarrollo de la región y del estado en general está el promover el desarrollo de aquellas industrias que pueden ofrecer el soporte que la agroindustria requiere, a nivel local o regional, para que el desempeño del eslabón productivo sea más eficiente y pueda generar eslabonamientos hacia atrás y hacia adelante en la economía nacional. Sobre todo, debe potenciarse el desarrollo de empresas proveedoras de insumos, formando redes de proveedores nacionales que se articulen a la agroindustria de hortalizas exóticas, como es el caso de la industria de jabas, con la cual se activarían otras empresas ligadas a esta otra industria. En el terreno de los fertilizantes y plaguicidas existe otra área de oportunidad para la 
región centro occidente mexicano y la posibilidad de utilizar el know how adquirido por la agroindustria para extender la cadena a otros nichos y mercados y/o a otros productos hortícolas.

En este mismo sentido, la agroempresa San Carlos es un actor fundamental en el desarrollo del sector al incorporar procesos que van más allá del eslabón productivo, además de ofrecer al sector agrícola de la región diversos servicios que ha incorporado en su proceso productivo, como la renta de maquinaria, servicios de esterilización de madera, de acopio y de transporte; estos dos últimos servicios permiten incorporar a la cadena a pequeños productores que de otra manera quedarían marginados.

Por otro lado, la necesidad de generar mayor valor agregado o apropiarse de un porcentaje mayor del valor generado dentro de la cadena debe ser una visión a mediano plazo, en la que debe participar el gobierno del estado estableciendo condiciones macroeconómicas adecuadas para alcanzar un nivel de estabilidad económica, entre las que estarían: destacar la oferta y accesibilidad de programas e instituciones de financiamiento para pequeños y medianos productores, tomando en cuenta que son muy pocos los productores que pueden acceder a estos recursos al no contar con los requisitos que los hacen sujetos de financiamiento, por lo cual se ven obligados a aceptar el financiamiento ofrecido por las empresas comercializadoras bajo condiciones poco favorables para ellos; en este sentido, la creación de instituciones financieras y fijación de tasas de interés reales competitivas en la economía nacional deben ser un objetivo prioritario para el gobierno, así como tasas de inflación bajas y políticas sectoriales que promuevan de manera activa el desarrollo de esta agroindustria al crear incentivos que busquen el desarrollo de I+D y susciten procesos de innovación en el sector. El mayor problema que enfrenta la agroindustria es el financiamiento, en este sentido, es necesario crear mecanismos que faciliten el acceso a los programas de financiamiento que ofrece el sector público a través de los fondos sectoriales y que las agroempresas puedan aprovecharlos para mantener un desarrollo más fuerte y sostenido en infraestructura, además de la creación de un fideicomiso que pueda estar a la disposición de ese sector y sirva como fondo para el desarrollo de innovaciones y de tecnología.

No se puede dejar de lado que, para el estado de Nayarit, el sector agrícola es una de las principales fuentes de empleo, por lo que se vuelve importante desarrollar más cadenas con un nivel de desarrollo semejante al de la agroindustria de hortalizas, la cual incorpora un alto nivel de tecnología como parte de su estrategia de competitividad. Además, también integra de manera más permanente a pequeños productores, no sólo a través de la renta de sus tierras, sino como parte de la producción necesaria para atender la demanda del mercado de hortalizas exóticas. Bajo este esquema, los pequeños productores pueden participar en el proceso de activar la economía regional y desarrollar capacidades que se pueden extender de manera más rápida en el sector en la medida en la que más productores se incorporen al proceso. $\mathbf{E}$ 


\section{REFERENCIAS}

Centro de Comercio Internacional (2003). Análisis de la cadena de valor: cómo aumentar el ingreso por exportaciones. Forum de Comercio Internacional, 1/2013. [en línea] Disponible en: <http://www.forumdecomercio.org/ An\%C3\%Allisis-de-la-cadena-de-valor-C\%C3\%B3mo-aumentar-el-ingresopor-exportaciones/>.

Dolan, C. y Humphrey, J. (2001). Governance and trade en fresh vegetables: Tle impac of UK supermarkets on the African horticulture industry. Development Studies, 37(2), pp.147-176.

Garammont, H.C. (2010). La evolución de la producción agropecuaria en el campo méxicano: concentración productiva, pobreza y pluriactividad. Andamios, 7(13), pp. 85-117.

Gereffi, G. (2001). Beyond the producer-driven/buyer-driven dichotomy: The evolution of global value chains in the Internet era. IDS Bulletin, 32(3), pp. 30-40.

Gereffi, G., Humphrey, J. y Sturgeon, T. (2005). The governance of global value chains. Review of International Political Economy, 12(1), pp. 78-104.

Gereffi, G., Korzeniewicz, M. y Korzeniewicz, R. (1994). Introduction: Global Commodity Chains. En: G. Gereff, M. Korzeniewicz y R.P. Korzeniewicz (eds.), Commodity Chains and Global Capitalismo (pp. 1-14). Westport, CT: Greenwood Publishing Group.

Gereffi, G., Lee, J. y Christian, M. (2009). US-based food and agicultural value chains and their relevance to healthy diets. Journal of Hunder \& Environmental Nutrition, 4(3-4), pp. 357-374.

Gereffi, G., Humphrey, J., Kaplinsky, R. y Sturgeon, T.J. (2001). Introduction: Globalisation, value chains and development. IDS Bulletin.Value of Value Chains, 32(3), pp. 1-17 (editado por G. Gereffi y R. Kapñinsky).

Pelupesy, W. (2001). El enfoque de la cadena global de mercancías como herramienta analítica en las economías en vías de desarrollo. Economía y Sociedad, 6(15) pp. 111-120.

Pérez, C. (2001). Cambio tecnológico y oportunidades de desarrollo como blanco móvil. Revista de la CEPAL, 75, diciembre, pp. 115-136.

Pérez, C. (2009). La otra globalización: los retos del colapso financiero. Problemas del Desarrollo, 40(157), pp. 11-37. 